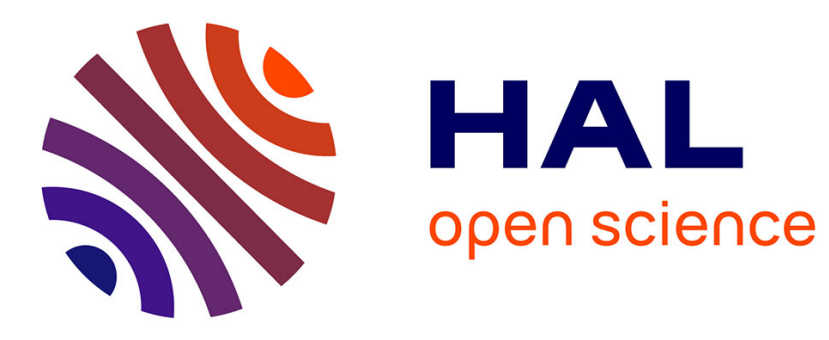

\title{
Unthresholded Recurrence Plots Analysis for Degradation Assessment of Power Cables Insulation
}

Y. Kemari, A. Mekhaldi, M. Teguar, G. Teyssedre

\section{To cite this version:}

Y. Kemari, A. Mekhaldi, M. Teguar, G. Teyssedre. Unthresholded Recurrence Plots Analysis for Degradation Assessment of Power Cables Insulation. 2018 IEEE 2nd International Conference on Dielectrics (ICD), Jul 2018, Budapest, Hungary. pp.1-4, 10.1109/ICD.2018.8514705 . hal-02396137

\section{HAL Id: hal-02396137 https://hal.science/hal-02396137}

Submitted on 25 Nov 2020

HAL is a multi-disciplinary open access archive for the deposit and dissemination of scientific research documents, whether they are published or not. The documents may come from teaching and research institutions in France or abroad, or from public or private research centers.
L'archive ouverte pluridisciplinaire HAL, est destinée au dépôt et à la diffusion de documents scientifiques de niveau recherche, publiés ou non, émanant des établissements d'enseignement et de recherche français ou étrangers, des laboratoires publics ou privés. 


\section{Unthresholded Recurrence Plots Analysis for Degradation Assessment of Power Cables Insulation}

\author{
${ }^{1}$ Y. Kemari, ${ }^{1}$ A. Mekhaldi, ${ }^{1}$ M. Teguar \\ ${ }^{1}$ Laboratoire de Recherche en Electrotechnique, \\ Ecole Nationale Polytechnique (ENP) \\ 10 Avenue Hassen Badi, B.P. 182, El-Harrach, Algeria \\ youcef.kemari@g.enp.edu.dz
}

\author{
${ }^{2} \mathrm{G}$. Teyssèdre \\ ${ }^{2}$ LAPLACE (Laboratoire Plasma et Conversion d'Energie), \\ Université de Toulouse, CNRS; Bat 3R3, 118 route de \\ Narbonne, F-31062 Toulouse cedex 9, France \\ gilbert.teyssedre@laplace.univ-tlse.fr
}

\begin{abstract}
Underground power cables have been widely used in transmission and distribution power systems, especially in urban areas. During their operating conditions, power cables are subjected to thermal, mechanical and electrical stresses. These stresses lead to accelerate the degradation process of the insulation material. In this paper, we present a novel methodology in the field that could be used to detect degradation level of power cables insulation due to thermal aging. In light of this, cross-linked polyethylene (XLPE) and polyvinyl chloride based compound (PVC, class B or PVC/B) were chosen as the studied materials. Thermal aging tests were performed at different aging temperatures $\left(80,100,120\right.$ and $\left.140{ }^{\circ} \mathrm{C}\right)$. Thereafter, the alternative bulk current through the aged samples was recorded at different aging stages and under $\mathrm{AC}$ applied voltage of $12 \mathrm{kV}$. For the aim to better analyze in-depth the obtained current waveforms, unthresholded recurrence plots (UTRPs) technique is introduced in order to extract features from the AC bulk current and reveal its characteristics. The obtained results show that the proposed method could be used as an assessment tool for current analysis and thermal degradation monitoring of insulation materials used in extruded power cables.
\end{abstract}

Keywords - Electrical insulation; dielectrics; thermal aging; cross-linked polyethylene; polyvinyl chloride; power cables; recurrence plot; diagnosis.

\section{INTRODUCTION}

The deterioration of extruded power cables insulation could be attributed to a variety of stresses from the surrounding environment (i.e external excess temperature, external radiation, humidity) [1]. In fact, the thermal constraint, which is mainly due to the heating effect from the conductor carrying load current [1], is often considered as the most harmful factor causing not only to the full deterioration of the power cable, but also to environmental and financial damage [2]. For this reason, many researches are focusing on the development of new nondestructive diagnostic methods for the aim to assess whether such cables have been electrically degraded due to thermal aging [3-5].

It is well known that the dielectric response of a cable insulation is a result of its capacitive and conductive properties. In fact, in conventional power cables, the voltage is applied between a central metallic conductor and an earthed metallic screen that surrounds it. The two components are separated by the insulation system [3]. Consequently, we suggest that the analysis of the bulk current signal through insulation materials could be applied for the degradation diagnosis of power cables. Moreover, several signal processing methods, known also as feature extraction techniques, could be used to study the characteristics of the current signal. Some of them privileged to extract features in the time domain, while others suggest the frequency one [6].

In the present work, we propose an experimental-signal processing methodology for evaluating the degradation level of the studied insulation materials. The methodology involves the record of the $\mathrm{AC}$ current waveforms in unaged and thermally aged XLPE and PVC/B samples. Unthresholded Recurrence Plots (UTRPs) method has been introduced for the first time in this area for the sake to characterize and identify the behavior of the AC current versus aging process. Indeed, UTRPs reflects the current shape, and thus the insulating state. By means of graphical structures, UTRPs is an effective technique to monitor and detect the critical degradation of cable insulation.

\section{EXPERIMENTAL TECHNIQUES AND PROCEDURE}

\section{A. Material and samples preparation}

XLPE and PVC/B compounds used in power cables are intended for voltages up to $36 \mathrm{kV}$ and $3.6 / 6 \mathrm{kV}$ respectively, according to IEC 60502-2 standard [7]. Crosslinked Polyethylene XLPE was supplied by General Cable, ENICAB factory of Biskra, Algeria. The insulation material, LE4201R compound, intended for voltages up to $36 \mathrm{kV}$ was delivered by Borealis, Austria. The melt temperature of the material is approximately $130{ }^{\circ} \mathrm{C}$, and it contains dicumyl peroxide (DCP) as crosslinking agent and Di-tert-butyl peroxide as antioxidant. On the other hand, PVC/B is manufactured by the electric cables factory CABEL in Algiers, Algeria, where Polyvinyl chloride resins (SE-1200) are blended with di-isodecyl phthalate (DIDP) plasticizer and Calcium-Zinc Stabilizer. XLPE and PVC/B plates were cut into circularly shaped samples using a cutting press. The samples have a thickness of $2 \mathrm{~mm}$ and a diameter of $46 \mathrm{~mm}$.

\section{B. Thermal aging experiments}

Thermal aging was performed according to the IEC 60216 standard [8]. For both materials, the circular samples were aged at three temperatures; 80,100 and $120^{\circ} \mathrm{C}$ using air-circulating ovens. For PVC/B, the aging time was $5040 \mathrm{~h}$ (210 days) at 80 and $100{ }^{\circ} \mathrm{C}$ against $1008 \mathrm{~h}$ (42 days) at $120^{\circ} \mathrm{C}$, corresponding 
to the mechanical properties deterioration of PVC/B. Due to its excellent thermal endurance, XLPE samples are exposed to an additional aging temperature of $140{ }^{\circ} \mathrm{C}$ for $2520 \mathrm{~h}$ (105 days).

\section{Experimental arrangement}

Current measurements were carried out in the high voltage laboratory of Ecole Nationale Polytechnique, Algiers, Algeria. The experimental setup is schematically presented in Fig. 1. The experimental setup consists of a high voltage test transformer $(50 \mathrm{kVA}, 300 \mathrm{kV}, 50 \mathrm{~Hz})$ supplied by a regulating transformer $(50 \mathrm{kVA}, 220 / 500 \mathrm{~V}, 50 \mathrm{~Hz})$ and a voltage capacitive divider constituted by two capacitances in series $\left(\mathrm{C}_{1}=400 \mathrm{pF}\right.$ and $\left.\mathrm{C}_{2}=1000 . \mathrm{C}_{1}\right)$.

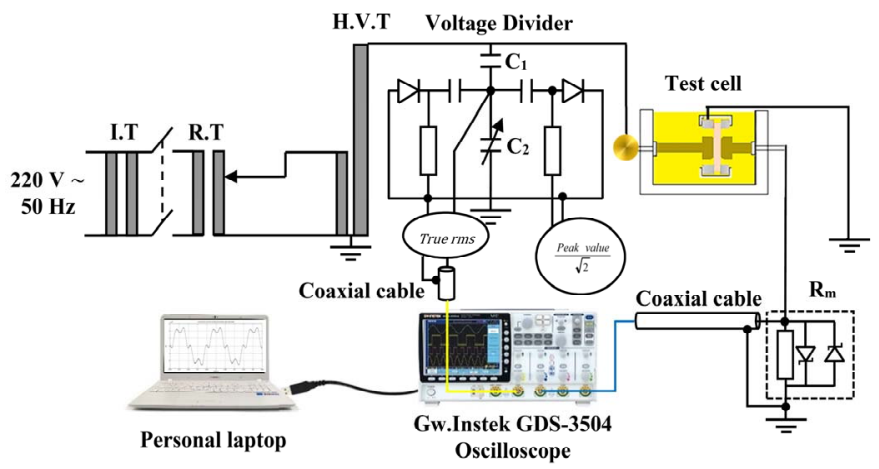

Fig. 1. Schematic diagram of the experimental set-up

As shown in Fig. 2, the prepared samples were mounted in an in-house made test cell between two electrodes of $25 \mathrm{~mm}$ in diameter with a grounder guard ring to prevent leakage current and provide homogenous electric field. The test cell is filled up with transformer oil in order to prevent external discharges and flashover. Acquisition of the AC bulk current waveforms was performed using Instek GDS-3504 4-CH Digital Storage Oscilloscope of $500 \mathrm{MHz}$ bandwidth. These waveforms are recorded across a shunt resistor of $R_{m}=1 \mathrm{k} \Omega$.
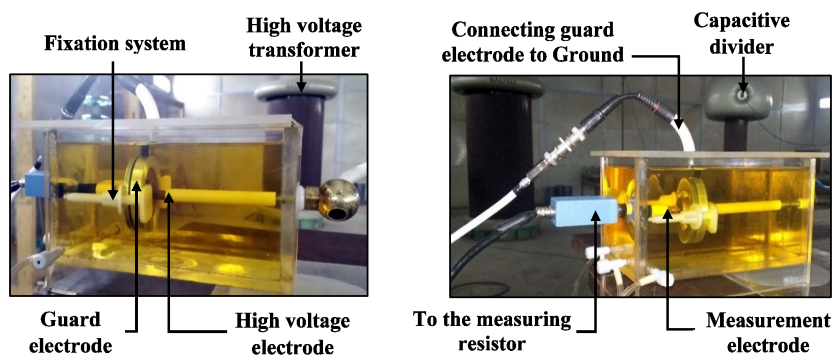

Fig. 2. View of the experimental set-up and the test cell

\section{UNTHRESHOLDED RECURRENCE PLOTS (UTRPS)}

Recurrence plot (RP) technique is a graphical tool used to visualize the recurrence behavior of phase space trajectory of a given time series. There are two distinct types of recurrence plots: unthresholded (UTRPs) and thresholded (TRPs) recurrence plots $[9,10]$. In a given m-dimensional phase space, the RPs are formed by comparing all embedded vectors with each other. If two state vectors lie in a neighborhood characterized by a threshold $\varepsilon$, the points are considered to be recurrent [6]. The embedding dimension $m$ has been chosen $m=1$ using false nearest neighbor algorithm [11]. The delay time $\tau$ was determined by the method of mutual information [12], where $\tau=20$. In UTRPs, points $(i, j)$ get a colored dot according to the distance between points $i$ and $j$ in the phase space $[9,10]$. First, the vector $\vec{x}_{i}$ can be reconstructed from a time series $x(i)$ as follows [6]:

$\vec{x}_{i}=[x(i), x(i+\tau), \ldots, x(i+(m-1) \tau], i=1, \ldots, N$

Where $N$ is the length of a time series, $m$ is the embedding dimension and $\tau$ is the delay time. Mathematically, for a given trajectory $x_{i}\left(i=1, \ldots, N, \mathrm{x} \in \mathrm{R}^{\mathrm{m}}\right)$, the recurrence matrix $R_{i, j}$ is defined as $[6]$ :

$R_{i, j}(\varepsilon)=\Theta\left(\varepsilon-\left\|\vec{x}_{i}-\vec{x}_{j}\right\|\right), i, j=(1, \ldots, N)$

Where $\|$.$\| is the norm (Euclidian norm is chosen is this work),$ $\Theta$ is the Heaviside function, $\mathcal{E}$ is threshold value and $x$ is the studied time series. As far as the threshold value $\varepsilon$ is concerned, many researchers concluded that $\varepsilon$ can be selected as $0.25 \sigma$ [6], where $\sigma$ is the standard deviation [3].

\section{RESULTS AND DISCUSSION}

This section is dedicated to presenting the experimental results of the obtained AC current waveforms. In addition, UTRPs is employed in order to extract further information about the current signals for XLPE and PVC/B materials. In this investigation, UTRPs is used for qualitative analysis of the current waveforms. The 2-D representation has distinct topologies and texture patterns. This offers the possibility to detect changes in the graphic patterns and structures with thermal aging. In the UTRPs, each color indicates a range of distances between states, i.e. the Euclidean distances between all vectors are mapped to colors as shown on the color bars of each UTRPs diagram. If the color code at the point is blue, then the points are located close to each other, and if the color code is red, the points are located farther apart.

\section{A. XLPE material}

The evolution of the current waveforms for XLPE before and after aging at $80,100,120$ and $140{ }^{\circ} \mathrm{C}$, under $12 \mathrm{kV}$ is illustrated in Fig. 3. Besides, Fig. 3 presents also UTRPs generated from the different current waveforms. It can be observed that aging has a very weak influence on the current magnitude at 80,100 and $120^{\circ} \mathrm{C}$. However, at $140{ }^{\circ} \mathrm{C}$, the current magnitude significantly increases. On the other hand, it has been found that the reason behind the shape of symmetrically distorted " $M$ " is the existence of odd order harmonics, essentially the $5^{\text {th }}(250 \mathrm{~Hz})$ and $7^{\text {th }}(350 \mathrm{~Hz})$ ones [3]. In UTRPs diagram, warm colors (red) can be associated with short distances between vectors, and contrarily cool colors (blue) can be associated with long distances. The diagonally oriented lines and the repeated structural elements in the plot indicate the periodicity of the current. Moreover, the system is perfectly predictable since the diagonal lines in the plot are long [13]. Furthermore, interesting "window" shape structures could be found in the vicinity of the main diagonal line (the 
Line of Identity LoI) as indicated with circles in Fig. 3e. The appearance of these shape structures is related to the " $\mathrm{M}$ " shape observed in the current waveforms which has been already explained by the existence of odd harmonics. It can be noticed that the topology is practically the same for the five cases. However, the intensity of the warm colors (red and yellow) increases with aging as the distances between points increases. This can be clearly noticed after $2520 \mathrm{~h}$ at $140{ }^{\circ} \mathrm{C}$ (Fig. 3e). In fact, the color bar that corresponds to the case of the most damaged sample (aged for $2520 \mathrm{~h}$ at $140{ }^{\circ} \mathrm{C}$, Fig. 3e) has been
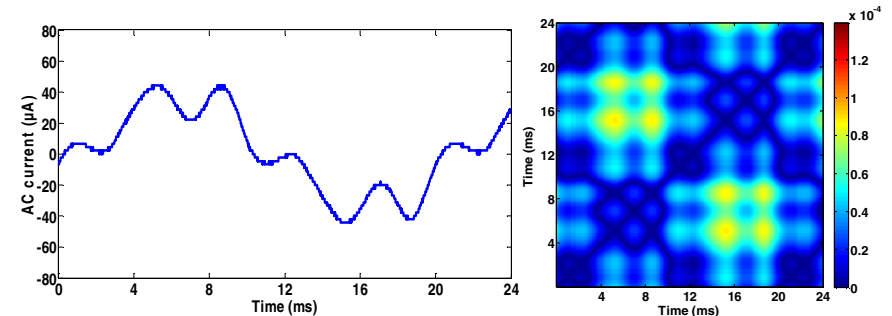

(a)
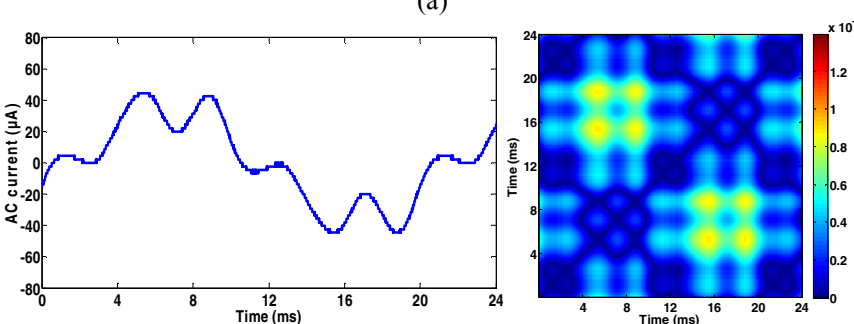

(b)
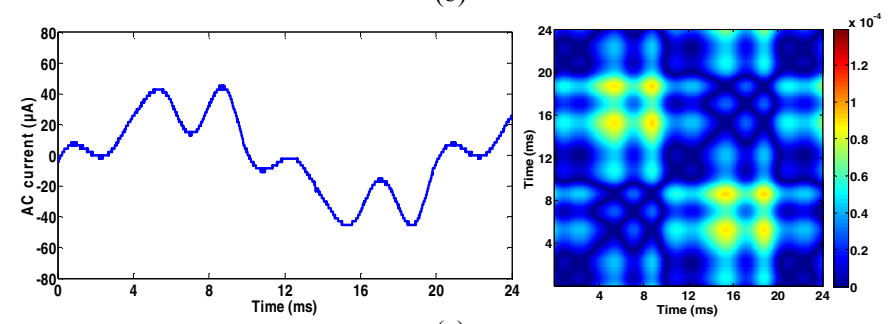

(c)
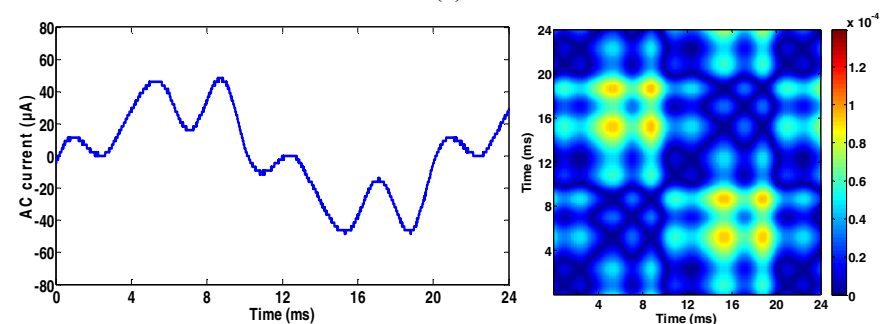

(d)
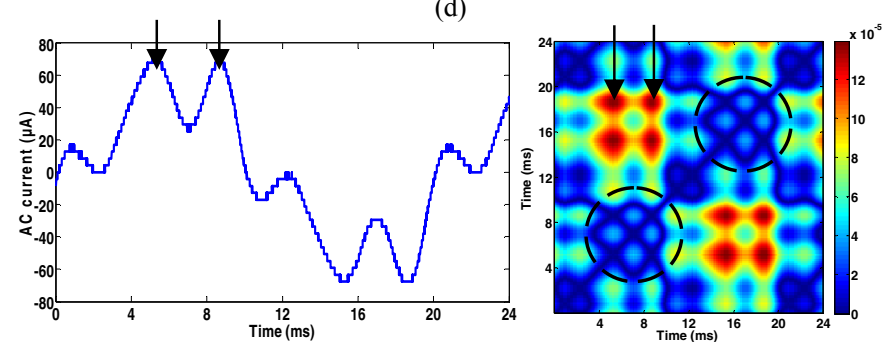

(e)

Fig. 3. From left to right, current waveforms and UTRP of the current for XLPE material under $12 \mathrm{kV}$ : (a) before aging, (b) at $80{ }^{\circ} \mathrm{C}$ for $5040 \mathrm{~h}$, (c) at $100{ }^{\circ} \mathrm{C}$ for $5040 \mathrm{~h},(\mathrm{~d})$ at $120^{\circ} \mathrm{C}$ for $5040 \mathrm{~h},(\mathrm{e})$ at $140{ }^{\circ} \mathrm{C}$ for $2520 \mathrm{~h}$ chosen as a reference color-bar. In another word, for the sake of better comparison, the color scale of Fig. 3e has been used for unaged and aged samples at 80,100 and $120{ }^{\circ} \mathrm{C}$. The distances are scaled to the value range $\left[0,1.29 \times 10^{-4}\right]$.

\section{B. $\quad P V C / B$ material}

As far as PVC/B is concerned, on the right left side of Fig. 4 , the evolution of current waveforms before and after aging at 80,100 and $120^{\circ} \mathrm{C}$ under $12 \mathrm{kV}$ is portrayed.
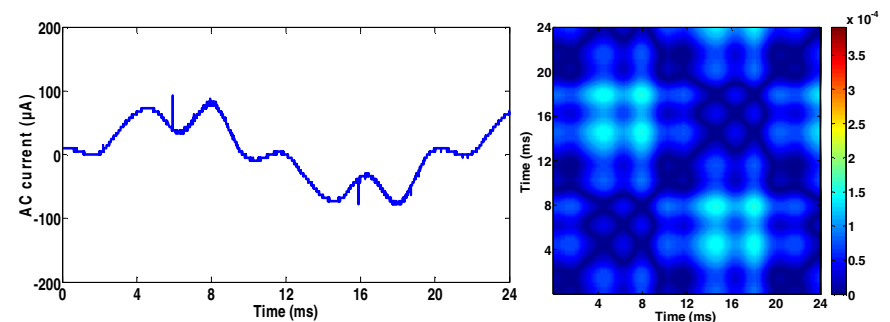

(a)
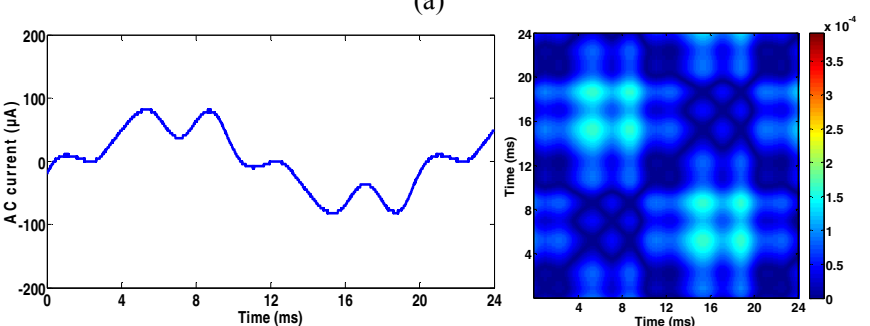

(b)
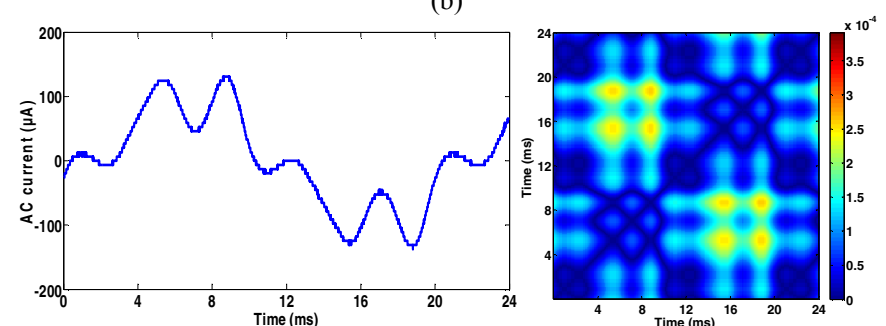

(c)
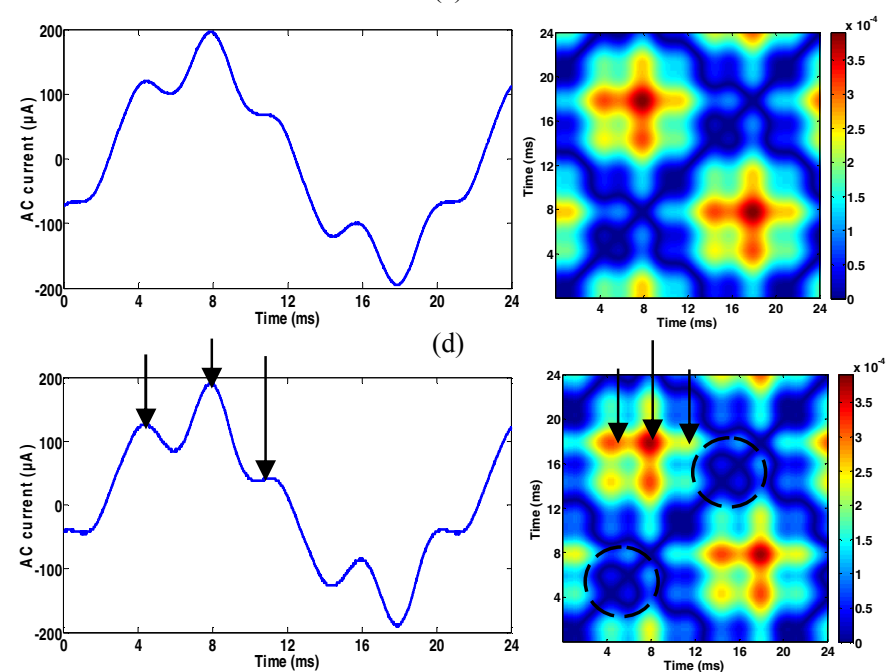

(e)

Fig. 4. From left to right, current waveforms and UTRP of the current for PVC/B under $12 \mathrm{kV}$ : (a) before aging, (b) at $80{ }^{\circ} \mathrm{C}$ for $5040 \mathrm{~h},(\mathrm{c})$ at $100{ }^{\circ} \mathrm{C}$ for $5040 \mathrm{~h},(\mathrm{~d})$ at $120{ }^{\circ} \mathrm{C}$ for $504 \mathrm{~h},(\mathrm{e})$ at $120^{\circ} \mathrm{C}$ for $1008 \mathrm{~h}$ 
On the right side of Fig. 4, UTRPs topologies of the current waveforms in PVC/B material are presented. The aging effect is significant on the current magnitude at 100 and $120{ }^{\circ} \mathrm{C}$. Furthermore, in the case of PVC/B samples aged at $120{ }^{\circ} \mathrm{C}$ after $504 \mathrm{~h}$ (Fig. 4d and 4e), the degradation is more accentuated. Indeed, it has been found that the $3^{\text {rd }}$ harmonic rises and its existence is considered to be more important with regard to $5^{\text {th }}$ and $7^{\text {th }}$ components. Therefore, the $3^{\text {rd }}$ harmonic becomes the most important harmonic component that could be used in order to characterize the critical degradation of the insulation [3]. We propose that the breakdown of $\mathrm{PVC} / \mathrm{B}$ becomes imminent when the $3^{\text {rd }}$ harmonic content increases [3, 14]. Moreover, in unaged and aged PVC/B samples at 80 and $100{ }^{\circ} \mathrm{C}$, the obtained graphic structures are the same obtained previously for XLPE material. These structures consist mainly of diagonally oriented lines and "window" shape structures (Fig. 4a, 4b and 4c). With regard to XLPE material, a significant change can be noticed in the UTRPs diagram color of $\mathrm{PVC} / \mathrm{B}$ at $100{ }^{\circ} \mathrm{C}$ after $5040 \mathrm{~h}$ of aging.

Nevertheless, at $120{ }^{\circ} \mathrm{C}$, the "window" shaped patterns have been disappeared and new structures have been obtained as indicated with circles in Fig. $4 \mathrm{c}$ and 4e. This recurrence structure could be attributed to the middle peak obtained in the current waveform. This peak is related to the appearance of the $3^{\text {rd }}$ harmonic component in the current, whereas $5^{\text {th }}$ and $7^{\text {th }}$ harmonics are always existing. A similar recurrence structure has been found by other researchers [15]. Additionally, the increase of the Euclidean distances between all recurrences points leads to the increase of the intensity of the warm colors. This last result contributes to the appearance of the "Octagram" shape which can be easily distinguished at 120 ${ }^{\circ} \mathrm{C}$. In fact, the increase of the distances between points indicates that the process is becoming more and more deterministic [15]. As a result, "Octagram" structure could be a good indicator of the advanced aging process. Similarly to XLPE, the color-bar corresponds to aged sample at $120{ }^{\circ} \mathrm{C}$ (Fig. 4e) has been used as a reference for better comparison. The distances are scaled to the value range $\left[0,3.85 \times 10^{-4}\right]$. It can be noticed that for unaged and aged PVC/B sample at 80 ${ }^{\circ} \mathrm{C}$, UTRPs show only the blue color with regard to unaged and aged XLPE sample at the same temperature. Moreover, at 100 and $120{ }^{\circ} \mathrm{C}$, the distance between points, for $\mathrm{PVC} / \mathrm{B}$ material, is higher than that of XLPE for a fixed position in the UTRPs diagram. This observation denotes that the degradation mechanism of $\mathrm{PVC} / \mathrm{B}$ versus thermal constraint is more rapid and significant than that of XLPE material.

The extension of UTRPs method from samples to cables would require recording the bulk current signatures in the cables as a function of time. Adaptation of the system would be possible using the central conductor as high voltage electrode and a coaxial cable connected to the grounded screen as the measurement electrode. A guard electrode could be used to avoid surface leakage current and any undesirable partial discharge phenomena to occur.

\section{CONCLUSION}

Unthresholded recurrence plot analysis was carried out on the AC bulk current. UTRPs diagram was evaluated for unaged and aged XLPE and PVC/B samples. The results show that the increase of the current magnitude is characterized by the appearance of red and black zones for both materials in UTRPs. Nevertheless, for PVC/B samples aged at $120^{\circ} \mathrm{C}$, new shaped structures appeared that might reflect the possibility of breakdown occurrence. The different geometries and topologies of UTRPs diagram could allow us to use these plots as a means of determining when the degradation of insulation materials becomes serious and intense. Thus, UTRPs analysis appears to be a sensitive tool to evaluate the insulation material quality. Future investigation will deal with recurrence quantification analysis method (RQA) to quantify the evolution of the AC bulk current dynamics versus thermal aging.

\section{REFERENCES}

[1] F. Aras, V. Alekperov, N. Can and H. Kirkici, "Aging of $154 \mathrm{kV}$ underground power cable insulation under combined thermal and electrical stresses," IEEE Electr. Insul. Mag, Vol. 23, No. 5, pp. 25-33, Sept.-Oct. 2007

[2] D. Wald, "Evolution of Medium Voltage Cable Technology in Europe", IEEE Electr. Insul. Mag., Vol. 24, No.5, pp. 31-35, 2008.

[3] Y. Kemari, A. Mekhaldi and M. Teguar, "Experimental investigation and signal processing techniques for degradation assessment of XLPE and PVC/B materials under thermal aging", IEEE Trans. Dielectr. Electr. Insul., Vol. 24, No. 4, pp. 2559-2569, 2017.

[4] G. Teyssedre and C. Laurent, "Advances in High-Field Insulating Polymeric Materials Over the Past 50 Years", IEEE Electr. Insul. Mag., Vol. 29, No.5, pp. 26-36, 2013.

[5] P. Werelius, Development and Application of High Voltage Dielectric Spectroscopy for Diagnosis of Medium Voltage XLPE Cables, PhD. Dissertation, Dept. Of Elec. Eng., Royal Institute of Technology, Stockholm, Sweden, 2001.

[6] A. K. Chaou, A. Mekhaldi and M. Teguar, "Recurrence quantification analysis as a novel LC feature extraction technique for the classification of pollution severity on HV insulator model", IEEE Trans. Dielect. Electr. Insul., Vol. 22, No. 6, pp. 3376-3384, December 2015.

[7] IEC 502, "Power cables with extruded insulation and their accessories for rated voltages from $1 \mathrm{kV}$ up to $30 \mathrm{kV}$ ", 2 $2^{\text {nd }}$ edition, 2004.

[8] IEC 60216, "Guide for the Determination of Thermal Endurance Properties of Electrical Insulating Materials. Part 1: General Guidelines for Aging Procedures and Evaluation of Test Result", $4^{\text {th }}$ Issue, 1991.

[9] H. Yang, "Multiscale Recurrence Quantification Analysis of Spatial Cardiac Vectorcardiogram Signals", IEEE Trans. Biomedical Eng., Vol. 58, No. 2, pp. 339-347, 2011.

[10] E. Cazares-Ibáñez, G.A. Vázquez-Coutiño and E. García-Ochoa, "Application of recurrence plots as a new tool in the analysis of electrochemical oscillations of copper", Journal of Electroanalytical Chemistry, Vol. 583, Issue 1, pp. 17-33, 2005.

[11] M. B. Kennel, R. Brown, H. D. I.Abarbanel, "Determining embedding dimension for phase-space reconstruction using a geometrical construction”, Phys. Rev. A 45, pp. 3403-3411, 1992.

[12] A. M. Fraser, H. L. Swinney, "Independent coordinates for strange attractors from mutual information", Phys. Rev. A, pp. 33, 1134-1140, 1986.

[13] D. Mayorga-Cruz, O. Sarmiento-Martínez, C. Menchaca, J. Uruchurtu, "Analysis of Michelson Optical Interferometry Using Recurrence Plots During Corrosion of Aluminium in $\mathrm{NaCl}$ Solution", Electrochemical Society Transactions, Vol. 20, No.1, pp. 433-446, 2009.

[14] T. Suda, "Frequency characteristics of leakage current waveforms of an artificially polluted suspension insulator", IEEE Trans. Dielectr. Electr. Insul., Vol. 8, No. 4, pp.705-709, 2001.

[15] C. Zhou and W. Zhang, "Recurrence Plot Based Damage Detection Method by Integrating Control Chart", Entropy., Vol. 17, No. 5, pp. 2624-2641, 2015. 